\title{
Study of the effect of temperature on diffusion of a liquid of simulation inside the polyethylene vinyl acetate
}

\author{
Rachid ATMANI ${ }^{1}$; M'hammed EL KOUALI ${ }^{1}$; Mohammed TALBI ${ }^{1}$; Abdlhak EL BROUZI ${ }^{2}$
}

\section{Abstract-Diffusion is the net movement of molecules} or atoms from a region of high concentration to a region of low concentration. This is also referred to as the movement of a substance down a concentration gradient.

In this study, the process of simulation liquid transfer is studied through the polyethylene vinyl acetate in two temperatures $\left(25^{\circ} \mathrm{C}\right.$ et $\left.45^{\circ} \mathrm{C}\right)$. The increase of temperature reduced the diffusion time. The diffusion kinetics of simulation liquid enter was analysed so as to determine the diffusion coefficient. The Arrhenius relation, with an activation energy value of three simulation liquids, expressed the effect of temperature on the diffusion coefficient.

Keywords - Temperature, diffusion, activation energy, polyethylene vinyl acetate

\section{INTRODUCTION}

Polymer Materials take a good place in the packaging field, so their contact with a liquid some matter transfer occur. The temperature is a factor that directly affects the transfer process, that's why we will study its influence on the diffusion by using the Arrhenius law.

The liquids of simulation used are: Ethanol, heptane and nitric acid.

Rachid ATMANI, M'hammed EL KOUALI, Mohammed TALBI are with Research Laboratory of Analytical Chemistry and Physical Chemistry of Materials, Faculty of Sciencers Ben M'sik, Hassan II University of Casablanca, Morocco

Abdlhak EL BROUZI is with Research Laboratory of Physical Chemistry and Bioorganic. Faculty of sciences and Techniques Mohammedia. Hassan II University of Casablanca, Morocco.

Corresponding author: E-mail: atmanirachid12@gmail.com. Mobil: $+212650030208$
The purposes of this study are:

- To examine the kinetics of diffusion of each liquid of simulation for two temperatures.

- Evaluate the diffusion coefficient and the activation energy for each liquid of simulation.

\section{MATERIALS AND METHODS}

\section{Mathematical modeling of diffusion}

\section{> Assumptions simplify:}

Assumptions are made for the process of diffusion of a liquid in a polymer, give as following [1] [2] [3] [4] [5]:

- The distribution is in accordance with fick's laws.

- The diffusion coefficient is independent of concentration.

- The diffusion in the sphere is radial.

- The polymer was spherical in shape with a constant radius, as the amount of a liquid is very small.

- The liquid does not evaporate on surface.

The total amount of diffusing substance going into or leaving the sphere is given by integrating Fick's first law according to time [1] [2] [7]:

$$
\frac{M_{\infty}-M_{t}}{M_{\infty}}=\frac{6}{\pi^{2}} \cdot \sum_{n=1}^{\infty} \frac{1}{n^{2}} \cdot \exp \left(-\frac{n^{2} \pi^{2}}{R^{2}} D t\right)(e q 1)
$$

For short times we use the following expression [1] [2] [7]:

$$
\frac{M_{t}}{M_{\infty}}=\frac{6}{R}\left(\frac{D t}{\pi}\right)^{0.5}(e q 2)
$$

Determination of the diffusivity of liquids of simulation

From the experimental results, we will calculate the diffusion coefficients D of liquid entering the PEVA.

The diffusion coefficient is calculated by using data obtained by the gravimetric method assuming Fickian type of diffusion for 
short time. The eq 2 is widely used to determine the diffusion coefficient of a penetrating solvent in a polymer to the establishment of a thermodynamic equilibrium between the polymer and the solvent. Indeed, tracing $\mathrm{M}_{\mathrm{t}} / \mathrm{M}_{\mathrm{eq}}=\mathrm{f}(\sqrt{\mathrm{t}})$ the slope $\alpha$ (linear portion of the kinetic for short time on the curve $\mathrm{M}_{\mathrm{t}} / \mathrm{M}_{\mathrm{eq}}=\mathrm{f}\left(V_{\mathrm{t}}\right)$ allows direct access to the diffusivity by the equation 3 : [4] [5]:

The equation used to determine that the diffusivity is [3]

$$
D=\pi\left(\frac{\alpha R}{6}\right)^{2} C m^{2} / s(e q 3)
$$

Tell that $\alpha$ : Is the slope of the line of the mass variation according to the square root

\section{Activation energy}

The influence of temperature on the diffusion coefficient (D) represented by the Arrhenius equation [6] :

$$
D=D_{0} \cdot \exp \left(\frac{-E_{D}}{R T}\right)(e q 4)
$$

Where $\mathrm{D}_{0}$ Is the diffusion coefficient at infinite temperature $(\mathrm{J} / \mathrm{mol}), \mathrm{E}_{\mathrm{D}}$ is the activation energy of diffusion, $\mathrm{T}$ is the temperature $(\mathrm{K})$ and $\mathrm{R}$ is the constant of perfect gases.

3. Experimental procedure

Follow the evolution of the amount of liquid inside the sphere in function of time until equilibrium [4] [5].

\section{RESULTS AND DISCUSSION}

The results are presented in terms of kinetics of diffusion for each liquid at two temperatures and the activation energy for three simulators.

\section{1. kinetics ofdiffusion and the diffusivity(table III last page)}

In Table I, we present the values of the diffusion coefficient $\mathrm{D}$ experimentally calculated at $\mathrm{T}=25^{\circ} \mathrm{C}$ and $\mathrm{T}=45^{\circ} \mathrm{C}$.

TABLE I: THE DIFFUSIVIT Y FOR EACH SIMULATOR AT TWO TEMPERATURES.

\section{The diffusivity in $\mathrm{cm}^{2} / \mathrm{s}$}

\begin{tabular}{ccc}
\hline $\begin{array}{c}\text { The } \\
\text { simulator }\end{array}$ & $\mathrm{T}=25^{\circ} \mathrm{C}$ & $\mathrm{T}=\mathbf{4 5}^{\circ} \mathrm{C}$ \\
Ethanol & $\mathbf{1 , 8 2 7 9 . 1 0}^{-6}$ & $\mathbf{2 , 2 4 2 9 . 1 0 ^ { - 6 }}$ \\
Heptane & $\mathbf{1 , 2 5 9 9 . 1 0}^{-6}$ & $\mathbf{2 , 4 4 1 3 . 1 0 ^ { - 6 }}$ \\
Nitric acid & $9,3344.10^{-7}$ & $\mathbf{1 , 2 0 7 4 . 1 0}^{-6}$ \\
\hline
\end{tabular}

2. Determination of activation energy

The diffusion coefficient can be connected to the temperature by the expression Arrhenius as follows [6] :

$$
D_{\text {eff }}=D_{0} \cdot \exp \left(-\frac{E_{a}}{R(T+273.13)}\right)(e q 5)
$$

With $\mathrm{D}_{0}$ is the constant in the Arrhenius equation (m2/ s), Ea is the activation energy $(\mathrm{kJ} / \mathrm{mol}), \mathrm{T}$ is the transfer temperature $\left(^{\circ}\right.$ C) and $\mathrm{R}$ is the ideal gas constant ( $\mathrm{kJ} / \mathrm{mol}$. K). The Eq223 can be rearranged as:

$$
\operatorname{Ln}\left(D_{\text {eff }}\right)=\operatorname{Ln}\left(D_{0}\right)-\frac{E a}{R(T+273.13)}(e q 6)
$$

$\mathrm{D}_{\text {eff }}$ values (eq6) calculated for the two temperatures are plotted on Figures in table 1 above for the three simulation liquids, which are straight in the temperature range studied, indicating the Arrhenius dependency.

Of the slope of these lines described by the Arrhenius equation, we deduce the activation energy for each simulation liquid.

By plotting a $\left(\mathrm{D}_{\text {eff }}\right)$ in function of $(1 / \mathrm{K})$ to determine the activation energy.

The three figures below represent the variation of $\ln \left(\mathrm{D}_{\text {eff }}\right)$ as a function of $(1 / \mathrm{K})$ for each simulation liquid.

\section{Ethanol}

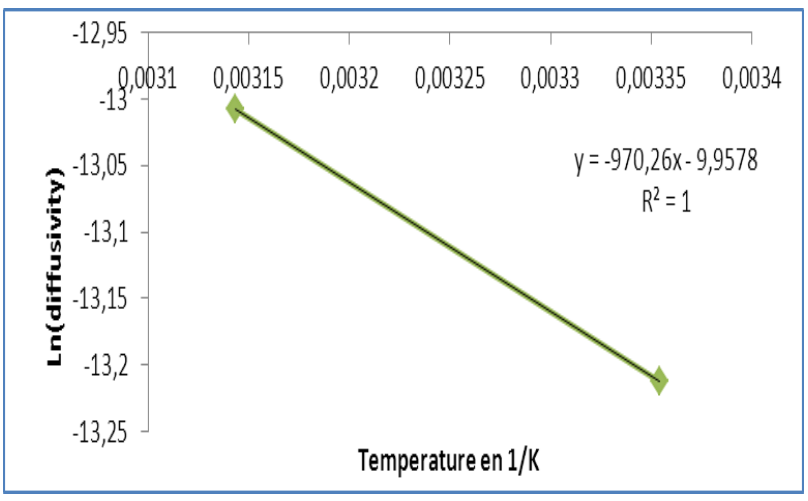

Fig.1. Influence of temperature on the coefficient of diffusion of ethanol

\section{Heptane}

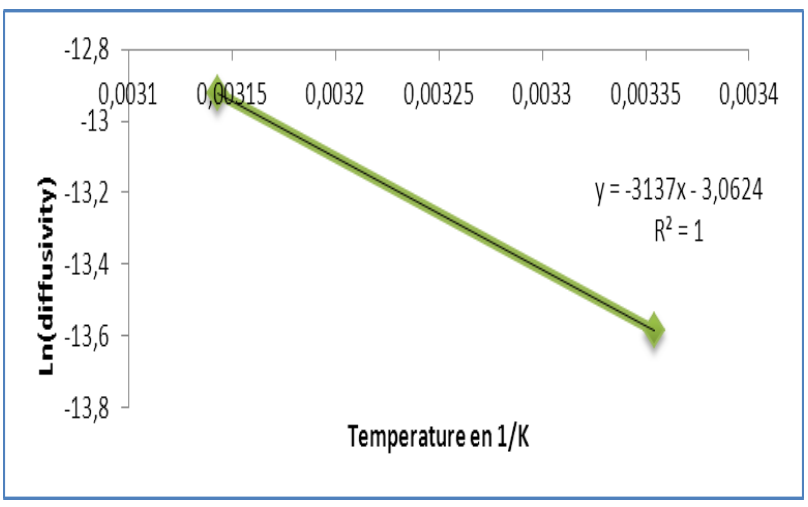

Fig.2. Influence of temperature on the coefficient of diffusion of heptane 


\section{Nitric acid}

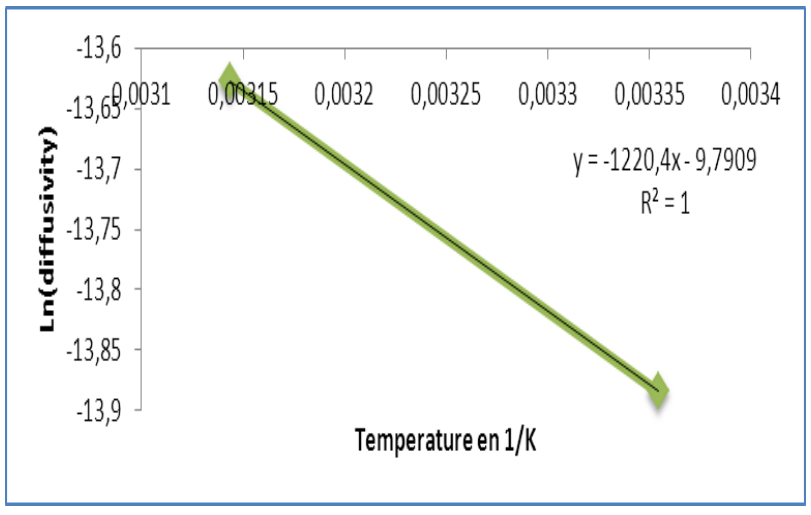

Fig.3. Influence of temperature on the coefficient of diffusion of nitric acid

The values of the activation energy for different simulation liquid are shown in table II:

T ABLE II: THE ACTIVATION ENERGY FOR THREE SIMULATORS

\begin{tabular}{cc}
\hline Simulator & $\begin{array}{c}\text { Energy of activation } \\
\text { Ea }(\mathbf{k J} / \mathbf{m o l})\end{array}$ \\
\hline Ethanol & $\mathbf{8 , 0 7 2 6}$ \\
Heptane & $\mathbf{2 6 , 0 9 9 8}$ \\
Nitric acid & $\mathbf{1 0 , 1 5 3 7}$ \\
\hline
\end{tabular}

In the three figures above, we observe that the temperature is the main factor affecting the kinetics of diffusion simulation liquid in the polyethylene vinyl acetate, according to Arrhenius law.

We note also that the diffusion coefficient increases strongly with the temperature of contact. This is consistent with the results from the literature. Indeed, the phenomenon of diffusion of a molecule in a polymer follows an Arrhenius type of activation process. The activation energy was calculated for each simulation liquid using the Arrhenius equation.

\section{CONCLUSION}

The diffusion experiments are done at two temperatures ( 25 and $45^{\circ} \mathrm{C}$ ). According to the results obtained, we note that the diffusion curves show the same variation.

The main factor influencing the diffusion kinetics of liquid of simulation enters is the temperature, meaning that when the temperature is high, the diffusion time decreases considerably.

The diffusivity for each liquid of simulation has been calculated for two temperatures 25 and $45^{\circ} \mathrm{C}$. The coefficient of diffusion increases gradually as the temperature of the air increases. The activation energy was calculated by using the Arrhenius equation for all simulators.

\section{REFERENCES}

[1]:J.M.VERGNAUD, «Liquid Transparent Process in Polymeric Materials. Modelling and Industrial Applications», Prentice Hall, Englewood Cliffs, NJ, 1991.

[2]:J.GRANK; « the mathematics of diffusion »; Clarendon press, oxford, chap.11 (1976).

[3]: Rachid ATMANI, «Ethanol Diffusion in Polyethylene Vinyl Acetate: Modelling and Experimentation», Global Journal of Science Frontier Research Chemistry, Volume 13 Issue 8 Version 1.0 (Year 2013).

[4]: Rachid ATMANI, «Diffusion of Heptane in Polyethylene Vinyl Acetate: Modelisation and Experimentation», IOSR Journal of Applied Chemistry (IOSR-JAC), Volume 7, Issue 6 Ver. I. (Jun. 2014), PP 82-86.

[5]: Rachid ATMANI, «Diffusion of nitric acid in Polyethylene Vinyl Acetate: Modelisation and Experimentation», International Journal of Advanced Scientific and Technical Research . Issue 4 volume 5, (Sep. \pm Oct.2014)

[6] : Limm, W. et Hollifield, H.C., 1996. Modelling of additive diffusion in polyolefins. Food Additives \& Contaminants: Part A: Chemistry, Analysis, Control, Exposure \& Risk Assessment 13(8), 949-967.

[7] : Etienne, S. et David, L., 2002. Introduction à la physique des polymères, Dunod, Paris (France).

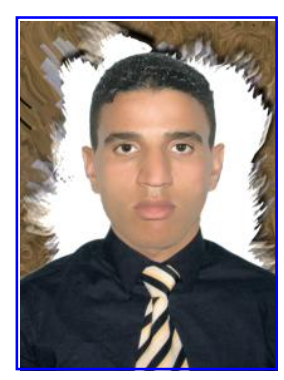

Rachid ATMANI, M'hammed EL KOUALI, Mohammed TALBI are with Research Laboratory of Analytical Chemistry and Physical Chemistry of Materials, Faculty of Sciencers Ben M'sik, Hassan II University of Casablanca, Morocco

Abdlhak EL BROUZI is with Research Laboratory of Physical Chemistry and Bioorganic. Faculty of sciences and Techniques Mohammedia. Hassan II University of Casablanca, Morocco.

Corresponding author: E-mail: atmanirachid12@gmail.com. Mobil: +212650030208 


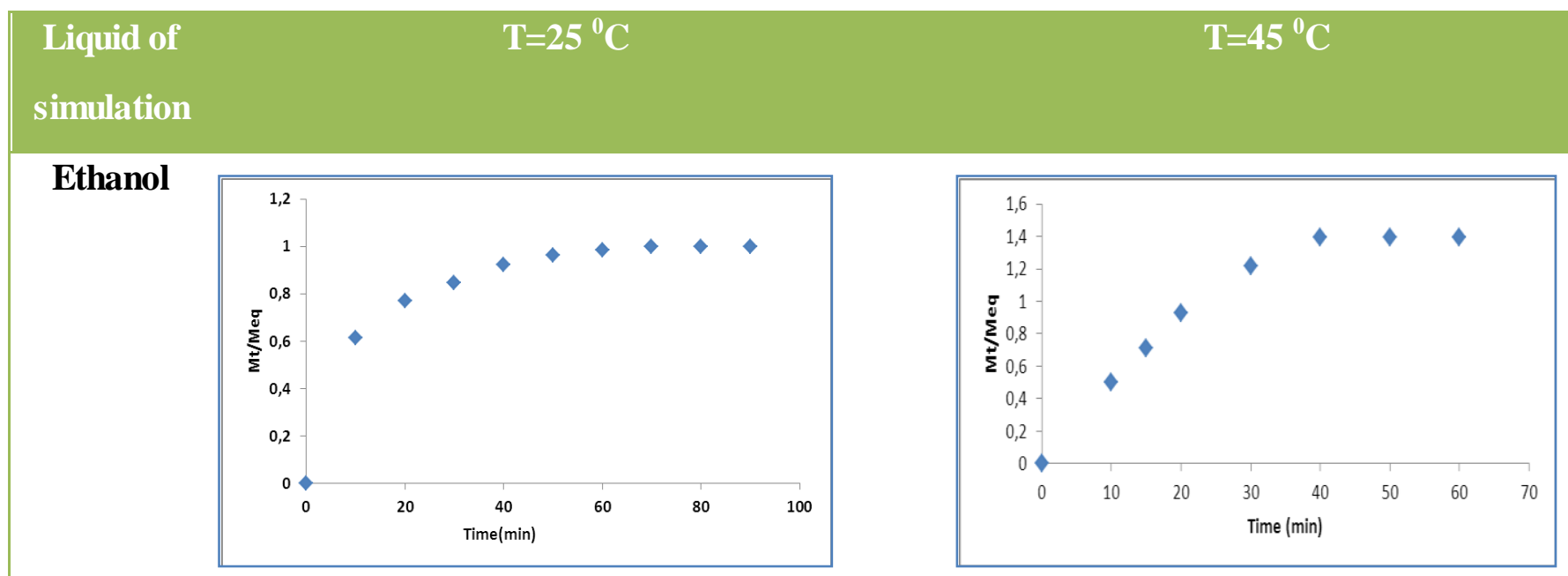

\section{Heptane}
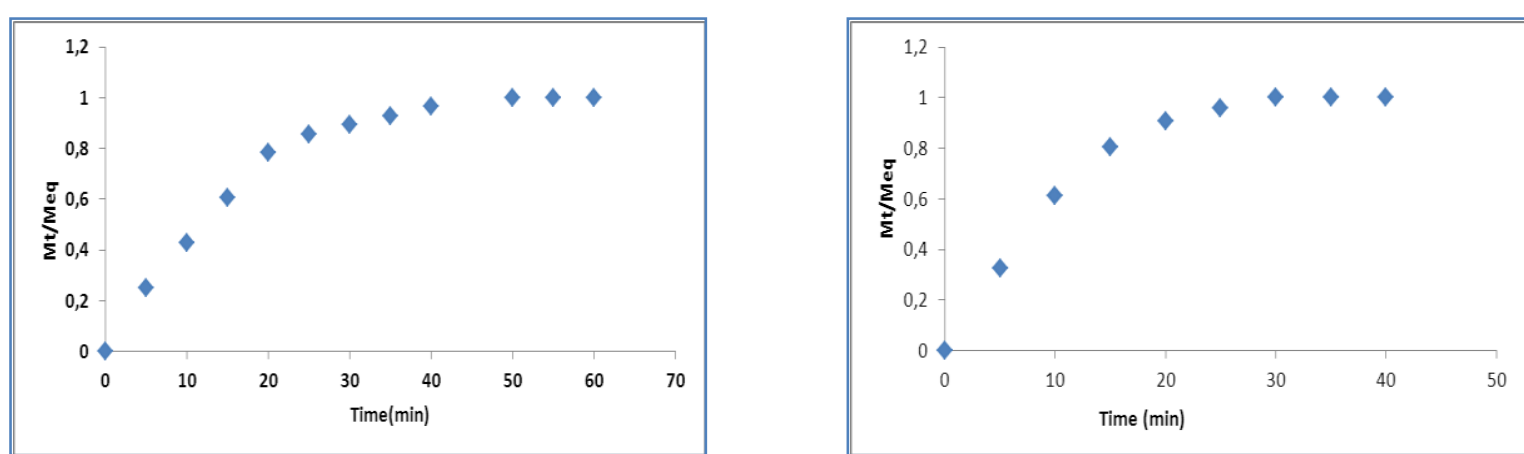

\section{Nitric acid}
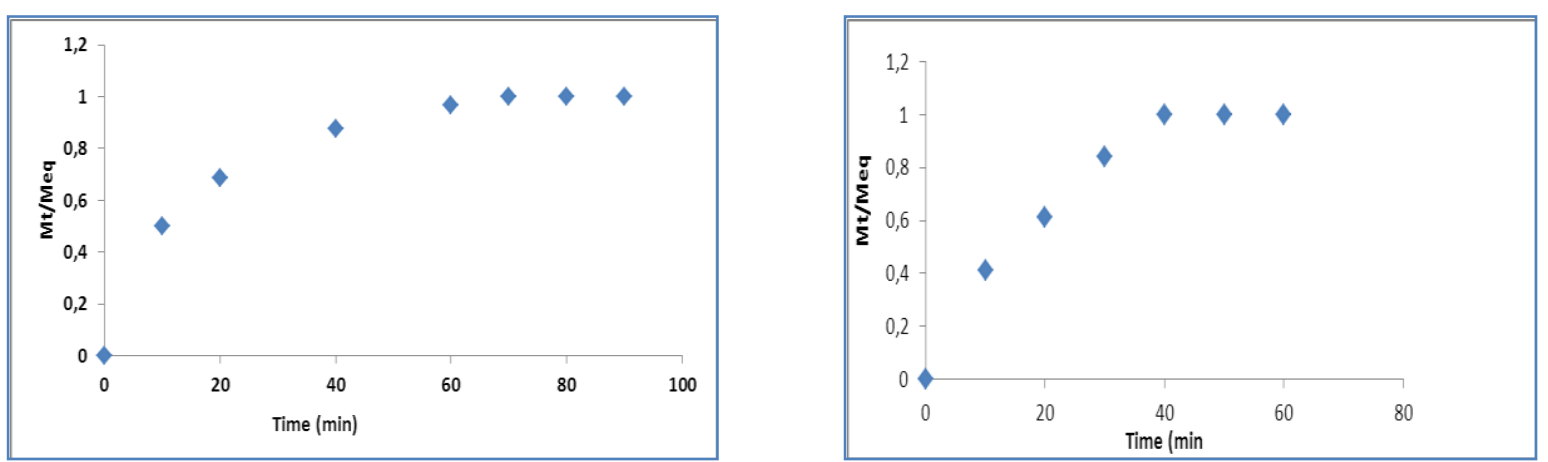